Proceedings of the 2003 Winter Simulation Conference

S. Chick, P. J. Sánchez, D. Ferrin, and D. J. Morrice, eds.

\title{
EVALUATION OF ARMY CORPS FOOD SUPPLY SYSTEM USING SIMULATION
}

\author{
Ozan Pembe \\ Training Center \\ 51. Brigade Dumlu \\ 25770 Erzurum, TURKEY
}

\author{
Ihsan Sabuncuoglu \\ Department of Industrial Engineering \\ Bilkent University \\ 06533 Ankara, TURKEY
}

\begin{abstract}
The Food Supply System is one of the main elements of the Army Logistics System. The ultimate objective in a food supply system is to provide the food at the right time and in the right amount at the right place. If this objective is achieved, the morale, the health, and the strength of the soldiers on the battlefield will enormously enhanced. The purposes of this study are to test if the existing food supply system of the Turkish Army operates properly under the war conditions; to identify the potential problem areas; and establish time standards for different scenarios. We use simulation as the modelling and analysis tool to answer the above questions. The proposed simulation model of the Army Corps Food Supply System is built in Arena and the results are analyzed statistically.
\end{abstract}

\section{INTRODUCTION}

Supply is a wide-ranging function that extends from determination of requirements at the national level down to delivery of items to the user in the theater. It involves activities at all levels of logistics. Supply of the force is one of the major elements in sustaining the battle. It is the process of providing all items necessary to equip, maintain, and operate a unit. Supply operations involve the storage, distribution, requisitioning, protection, maintenance, and salvage of supplies. As the battle progresses, logistic support units must provide the right supplies at the right locations on time to contribute to the fight. It is imperative that the systems be in place to allow the supported units to place their demands rapidly and to assist the logistic support units in providing the supplies in a timely manner.

Although there are many studies about logistic activities in simulation literature, only a few studies analyze these activities under the threat of enemy weapons. In this study, the Corps Food Supply System of Turkish Army is analyzed under enemy attacks. Müslüm and Sabuncuoğlu (2001) study the mobilization and deployment system of an armored battalion and identify the important factors of enemy threat. In another study, Kang and Gue (1997) develop a simulation model of the off-load of supplies to support a Marine Air-Ground Task Force to determine the number and allocation of different material handling devices for such an operation. Parker and Williams (1997) evaluate the steadystate logistics flow of fuel and ammunition through time.

In this study, we develop a simulation model of the Army Corps Food Supply System (ACFSS) to understand the behavior of the existing food supply system under war conditions, establish the nature of relationships among significant factors and the system performances, estimate time requirements of supply activities so that the necessary time standards can be established, and test new alternative supply policies to improve the system performance. Specifically, the following research questions are investigated using the proposed simulation mode:

- Does the existing system operate properly?

- What are the major problem areas (or bottleneck places) in the system?

- How do artillery and air attacks of enemy affect the system performances?

- What happens if we change the organization of the facilities in the ACFSS?

- What are the important factors that affect the system performance measures?

The rest of the paper is organized as follows: In Section 2, the Army Corps Food Supply System is described. Model development and verification/validation processes are also discussed in this section. The experimental design and results of the ANOVA tests are given in Section 3. In Section 4 we discuss the ranking and selection procedures to select the best alternative design using the Analytic Hierarchy Process (AHP) technique. Concluding remarks and future research directions are given in Section 6.

\section{SYSTEM DESCRIPTION AND MODELLING PROCESS}

In the existing system considered in this study, Battalion Personnel Officer reports the number of soldiers in each 


\section{Pembe and Sabuncuoglu}

company to the Personnel Office Administrator (POA) in the Brigade. The POA sends the information (the total number soldiers) to the Quartermaster Office Administrator which prepares the Ratio Demand of Brigade. This daily information determines the amount of food needed for the Brigade for the following day of operation. Then a convoy which consists of $8-10$ vehicles is formed to supply the subsistence needed by the brigade. The convoy starts its movement from the Brigade Supply Point (BSP) and may undergo different enemy attacks during its travel toward the Corps Supply Point (CSP). When it arrives at CSP, the convoy commander gives the requisition form which shows the Daily Ratio Demand of Brigade to the Food Supply Point Commander. FSPC orders the loading section to load the convoy. After completion of loading each vehicle, the convoy travels back to the Brigade Supply Point and may be attacked by enemy forces during its travel again. When convoy reaches the BSP, the loading/unloading units of BSP unload the vehicles. The food is separated into piles which belong to a specific battalion. Then each pile is loaded upon the vehicles of the Battalions. Each battalion convoy which comprises 2 or 3 vehicles travels toward the battalion region under the threat of enemy attacks. When these convoys arrive at their regions, the mission is complete.

In the military organization modelled in this study, there are 6 brigades, which are supplied by the Corps Supply Point, and each brigade has 3 battalions. There are 3 Food Supply Points in the CSP. These are 1000-1500 meters away from each other. One of them is the main supplier and supports 2 brigades. The others support 4 brigades but don't always have the required amount of food in its depots.

\subsection{Model Development}

In order to develop the simulation model, we first work on the conceptual model. Specifically, we understand main structure of the system and identify the important elements and their relationships. The main entity of the system is the vehicle of the brigade. The enemy planes and cannons are the entities which are used for the purpose of animation. Brigade and battalion identification numbers and damage types are considered to be the attributes of the system. The performance measures are time-in-system of the last vehicle reaching the battalion region and the number of destroyed vehicles. After the conceptual model we construct the logical model of the Food Supply System by the help of flowcharts. The logic of the model is as follows. The Food Supply System starts at 7 o'clock in the morning and ends when the last vehicle arrives at the battalion region. After the Convoy Commander (CC) takes the order from the brigade, the convoy marches toward the CSP. During traveling, the convoy may undergo two kinds of enemy attacks: artillery assault and air assault. If the artillery con- centration is at the back of the convoy, the vehicles increase their speed. Then, the $\mathrm{CC}$ stops the movement of convoy and waits until the artillery or air assault of the enemy finishes. At this point, CC checks whether there is any shot vehicle. If there is a damaged vehicle that is repairable, the repair team of the convoy fixes the vehicle. When a breakdown event occurs, the failed vehicle is again checked whether it is repairable or not. If it is repairable, it is repaired by the repair team of the convoy. When convoy arrives at the CSP, loading activities begin. After the CC gives the report to the FSP commander, the loading team in the FSP is checked whether it is idle or busy. If it is idle, loading begins. At the end of loading all vehicles of convoy, the CC orders convoy to march toward the brigade supply point (BSP). During traveling back to the BSP, the convoy may again undergo enemy attacks. After the convoy arrives at the BSP, unloading of vehicles begins.

As the last stage in the modelling process, we write the simulation code in ARENA since this software is a powerful and flexible tool in creating animated models and offers reasonably good simulation output facilities.

\subsection{Input Data Analysis}

In this study, we analyse the supply system under war conditions. But, our Army have not experienced any full-scale war for the last 80 years. Thus we face with the problem of real data. In the literature, triangular and uniform distributions are usually recommended in the absence of data (Banks 1998). We use these distribution functions by consulting with experts in the field. Some of the data sets for loading and unloading activities are taken from the army field manuals. We obtain the hit and kill probabilities of weapons used by the typical enemy forces from the databases of JANUS combat software.

\subsection{Output Data Analysis}

Because of the way that we anlayse the system, the Army Corps Food Supply System is a terminating system. It starts with a well specified initial condition (i.e., the current status and the march order of the convoys) and finishes when the last vehicle arrives to the battalion region. The simulation run length is six hours of the system operation. Since the simulation run length can not be manipulated in the terminating system, we achieve the desired accuracy by incresing the number of replications. We employ the sequential procedure discussed in Law and Kelton (2000) to set the sample sizes. Our experiments indicate that 15 replications are enough to estimate the performance measures with the 95 percent confidence level. 


\subsection{Verification and Validation}

The process of determining the correctness of a model consists of two functions: verification and validation. Verification is the process of determining that a model operates as intended. Validation is the process of determining that we have built the right model.

Verification is concerned with building the model right. Throughout the verification process, we try to remove unintentional errors in the logic of the model. The ARENA debugger function helps us to see whether the events occur properly or not. In addition, we test our model under extreme conditions to see if the model behaves reasonable. For instance, we increase the hit probabilities of the enemy weapons to 1 so that the average number of destroyed vehicles also becomes a large number. We also use the animation facility to find the errors.

In the validation process, we first apply face validity to check if our model looks reasonable to the personnel who are knowledgeable about the system. Potential users of a model are involved in the process to ensure that a high degree of ealism is built into the model. Thus we assure that the model behaves as expected. The outputs of the simulation model is found quite reasonable by the officers in the Logistics Information Systems Center. Additionally, we check the behavior of the system by performing sensitivity analysis on the loading times in the CSP. For example, we increase the loading times in corps supply point and observe that this causesan increase in the maximum time-insystem measure. Both the face validity and the sensitivity analysis indicate that our model has an accurate representation of the real supply system and it behaves as expected.

\section{EXPERIMENTAL SETTING}

Literally, an experiment is a test. A designed experiment is a test or series of tests in which purposeful changes are made to the input variables of a system so that the analyst may observe and identify the reasons for the changes in the output response (Montgomery 1991). In our case, we focus on the following research questions:

- How do artillery and air attacks of enemy affect the system performances?

- What happens if we change the organization of the facilities in the food supply system?

- What are the significant factors and how do they affect the system performance measures?

To answer the above questions, we implement $2^{\mathrm{k}}$ factorial design for five factors. Factor $A$ is the march technique on which the Convoy Commander of the vehicles decides. We consider two cases: split and group. In the split case, the vehicles don't wait for the down or damaged vehicles to be repaired and go on their march. In the second case, the convoy moves in-group. Hence, in the group case, the convoy cannot split and goes on its movement in integrity. Factor $B$ is the number of food supply points in Corps Supply Point. Factor $C, D, E$ are enemy artillery attack, enemy air attack and the usual breakdowns, respectively. The levels of the factors and their descriptions are given in Table 1.

Table 1: Description and Levels of Factors

\begin{tabular}{|c|l|l|l|}
\hline FACTORS & $\begin{array}{c}\text { FACTOR } \\
\text { DESCRIPTION }\end{array}$ & Low & High \\
\hline A & March Technique & Split & In Groups \\
\hline B & $\begin{array}{l}\text { Number of Supply } \\
\text { Points in CSP }\end{array}$ & 1 & 3 \\
\hline C & Artillery Assault & 0 & 0.2 \\
\hline D & Air Assault & 0 & 0.15 \\
\hline E & Breakdown & 0.05 & 0.2 \\
\hline
\end{tabular}

We conduct experiments at 32 design points with 15 simulation replications at each design point and calculate the effect of each factor and their interactions with each other. We implement the analysis of variance (ANOVA) to identify the factor(s) that has significant effects on the system performance. To ensure the independence, we used the replication element of ARENA. The performance measures are maximum time-in-system (MTIS) and number of destroyed vehicles. Before the evaluation of these ANOVA results for each performance measure, we check the validity of two important assumptions of ANOVA: the normality of the errors and the homogeneity of variances across the treatments. These assumptions are satisfied by examining the residuals and applying the Bartlett test.

\subsection{Results of Maximum \\ Time in System (MTIS)}

The results indicate that march technique, number of food supply points in Corps Supply Point, enemy attacks, and the usual breakdown are significant factors. All these factors have positive effects on the MTIS measure and march technique bas the greatest effect (see Figure 1).

It is interesting that MTIS increases when there are three food supply points in the CSP. When the number of food supply points (Factor $B$ ) is three, one of the FSPs operates as the main point and serves only for the third and fourth brigade convoys. The first, the second, the fifth, and the sixth brigade convoys are served by the remaining two FSPs. The remaining two FSPs do not have the all needed food in their depots. Therefore, some of the vehicles of $1^{\text {st }}$, $2^{\text {nd }}, 5^{\text {th }}, 6^{\text {th }}$ brigade convoys have to be served from main FSP. But these vehicles have to wait for the $3^{\text {th }}$ and $4^{\text {th }}$ bri- 


\section{Pembe and Sabuncuoglu}

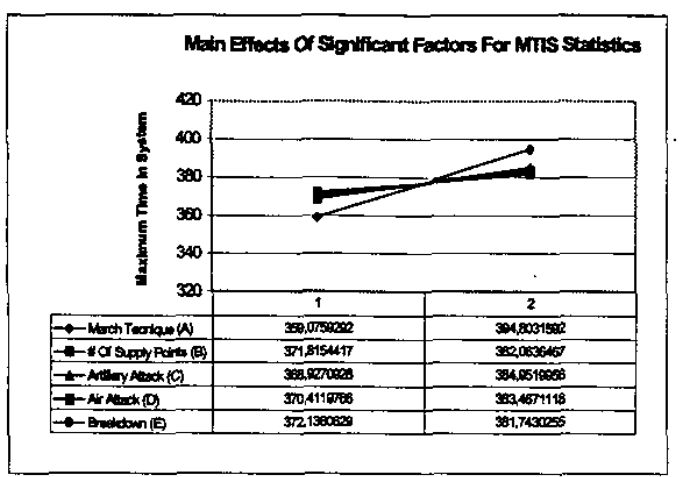

Figure 1: ANOVA Results for MTIS

gade convoys to be loaded first. If the number of FSPs is one, none of the convoys has priority over the other convoys. Because there are six loading teams inside this FSP and each of these teams will only serve one brigade convoy.

We conclude that when factor $B$ is at its high level, some of the vehicles from $1^{\text {st }}, 2^{\text {nd }}, 5^{\text {th }}, 6^{\text {th }}$ brigade convoys have to move toward the main FSP and have to wait for the $3^{\text {th }}$ and $4^{\text {th }}$ brigade convoys to be loaded. Hence, these activities will cause maximum time-in-system to increase. We also found that the interactions between the march technique and the number of FSPs, the march technique and the enemy air attack, and the march technique and the breakdown factor are significant. Because of the interaction between factor $A$ and factor $B$, the interpretation of main effects of factor $A$ and factor $B$ is more difficult as some interactions may mask the significance of main effects. In our study, the average of MTIS across the treatments when factor $A$ is at its low level is 359.07 . But when both factor $A$ and factor $B$ is at low levels, the average of MTIS decreases to 345.61 and when factor $A$ is at low level again and factor $B$ is high level, the average of MTIS increases to 372.53 at this time. It means that while the convoys march in split form, they do not wait so much in the loading queues when there is one FSP (low level (split) cause the average waiting time at FSPs to decrease and this change will decrease the MTIS either.

Time is one of the most important criteria in making logistic plans. The information generated from our simulation model indicates that staff officers who are assigned to prepare these plans should carefully examine the effects of enemy attacks, breakdowns, and especially the choice of the march technique. If the technology which makes the control, coordination, and command activities of convoys easy exists, planners should prefer the split form during the decision process for the appropriate march technique. As stated before, occurrence of enemy attacks means there will be failed vehicles to be repaired. Hence, this will cause time measure to increase. If security precautions of convoys during traveling are enhanced, the damage taken by these enemy attacks will be less. Breakdown causes time measure to increase significantly. Therefore, the maintenance of vehicles in peace time carries a great importance.

\subsection{Results of Number of Destroyed Vehichles}

Artillery and air attacks of enemy are significant factors for this performance measure. There is also a slight interaction between these factors. Since the kill probability in air attacks is higher than the one in artillery attacks, the average number of destroyed vehicles due to air attack is more than the average number of vehicles which is destroyed by enemy artillery attack.

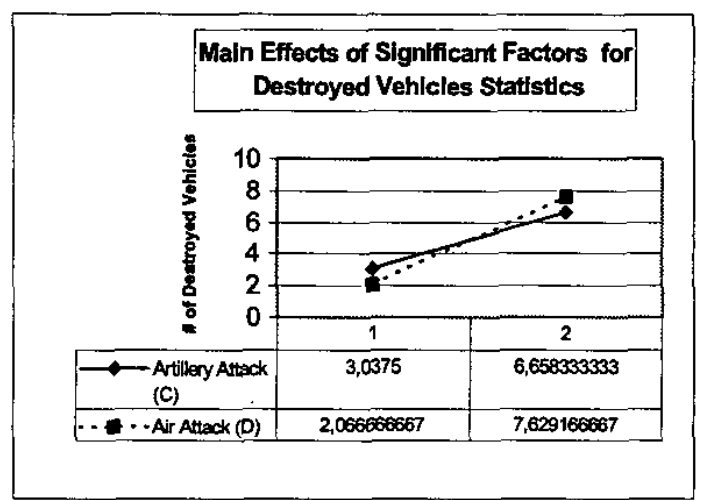

Figure 2: Results for Destroyed Vehicles

The results indicate that enemy attacks may be handicap of the supply system. In order to prevent the enemy attacks, the commander must give more emphasis on the reconnaissance activities. Since supply points are well protected against the artillery and air attacks of enemy, the convoys are usually safe when they arrive the FSPs. Selection of the march technique doesn't affect the occurrence of enemy attacks. Hence, this factor is also insignificant for the number-of-destroyed-vehicles measure. During model development, we assume that engines of the vehicles are in good condition. The results obtained from experiments indicate that the average number of destroyed vehicles across all treatments as a result of breakdown is mostly zero. That is why breakdown factor is insignificant in this case. In a war, it is likely that the artillery and air attack plans of enemy will be independent from each other. Hence, it is usual to observe insignificant interaction between these factors. All of these results are summarized in Table 2.

\subsection{Sensitivity AnalysIs}

We also investigate whether the results for MTIS is sensitive to the changes in the variances of loading distributions. As seen in Table 3, MTIS and average time-in-system measures do not follow a definite pattern of changes. It means that if the loading activities are performed with 


\section{Pembe and Sabuncuoglu}

Table 2: Significant Factors and Interactions for Performance Measures

\begin{tabular}{|l|l|c|}
\hline \multicolumn{1}{|c|}{$\begin{array}{l}\text { Factors and } \\
\text { Interactions }\end{array}$} & MTIS & DEST. \\
\hline $\begin{array}{l}\text { March } \\
\text { Technique }\end{array}$ & Significant & Insignificant \\
\hline $\begin{array}{l}\text { Number of FSPs } \\
\text { Artillery Assault }\end{array}$ & Significant & Insignificant \\
\hline Air Assault & Significant & Significant \\
\hline $\begin{array}{l}\text { Breakdown } \\
\text { March } \\
\text { Technique } \\
\text { Number of FSPs }\end{array}$ & Significant & Insignificant \\
\hline $\begin{array}{l}\text { March } \\
\text { Technique } \\
\text { Artillery Assault }\end{array}$ & Significant & Insignificant \\
\hline $\begin{array}{l}\text { March } \\
\text { Technique } \\
\text { Breakdown }\end{array}$ & Significant & Insignificant \\
\hline $\begin{array}{l}\text { Artillery Assault } \\
\text { Air Assault }\end{array}$ & Insignificant & Significant \\
\hline
\end{tabular}

Table 3: Sensitivity Analysis

\begin{tabular}{|c|c|c|c|c|}
\hline $\begin{array}{c}\text { Points of } \\
\text { Experiment }\end{array}$ & Mean & Var & MTIS & ATIS \\
\hline tria(8.0,10,12.0) & 10 & 0.6666 & 378.08 & 321.64 \\
\hline Tria(8.2,10,11.8) & 10 & 0.5400 & 384.92 & 324.78 \\
\hline Tria(8.4,10,11.6) & 10 & 0.4266 & 385.25 & 323.50 \\
\hline Tria(8.6,10,11.4) & 10 & 0.3266 & 385.11 & 323.56 \\
\hline Tria(8.8,10,11.2) & 10 & 0.2400 & 377.83 & 321.54 \\
\hline Tria(9.0,10,11.0) & 10 & 0.1666 & 390.85 & 325.54 \\
\hline Tria(9.2,10,10.8) & 10 & 0.1066 & 394.88 & 329.90 \\
\hline Tria(9.4,10,10.6) & 10 & 0.0600 & 391.98 & 330.56 \\
\hline Tria(9.6,10,10.4) & 10 & 0.0260 & 380.50 & 322.04 \\
\hline Tria(9.8,10,10.2) & 10 & 0.0066 & 381.31 & 322.16 \\
\hline Tria(10,10,10) & 10 & 0.0000 & 378.61 & 322.37 \\
\hline
\end{tabular}

equipment such as forklifts, the variability in the loading times will be reduced but this does not have a significant positive affect on maximum time-in-system measure in our system

\section{COMPARISON OF ALTERNATIVES}

Deciding on the number of FSPs and the march technique is a critical decision for staff officers who prepare logistic plans. In our case, we have four alternatives (see Table 4) among which is Alternative 4 is the existing system.

Table 4: Alternative Designs for The Army Corps Food Supply System

\begin{tabular}{|c|c|c|}
\hline Alternative & Number of FSP & $\begin{array}{c}\text { March } \\
\text { Technique }\end{array}$ \\
\hline 1 & 1 & Split \\
\hline 2 & 3 & Split \\
\hline 3 & 1 & Group \\
\hline 4 & 3 & Group \\
\hline
\end{tabular}

Our pilot simulation runs indicate that Alternative- 1 is the best of all. But according to our military experts, having just one supply point in the CSP and moving in split form might be disadvantageous. If this single FSP is destroyed by the long-range weapons of enemy, there will be unfortunately no food to supply. It is obvious that single FSP is better and tempting target for enemy to attack. However, vulnerability to enemy attacks is high when there is just one FSP. Another issue, discussed by the experts is that moving in split form may lead to some problems in the command, control and coordination (CCC) activities of the brigade. The experience obtained from military exercises indicates that moving in group causes the CCC activities to be performed conveniently.

Making a decison using only the MTIS measure may lead to erroronus conclusions. The CCC activities and the vulnerability to enemy attacks also emerge as two important criteria in the decision making process. Thus, we consider all three criteria in selecting the best alternative. We apply Analytic Hierarchy Process (AHP) technique (Saaty, 1988). Since the three criteria are not equally important for the experts, we determine weights for each performance measure and rank the alternatives.

The results indicate that Alternative- 2 is the best alternative in which there are three FSPs and convoys move in the split form (see Table 5). 
Table 5: Results of AHP

\begin{tabular}{|c|c|c|c|c|}
\hline & Alt 1 & Alt 2 & Alt 3 & Alt 4 \\
\hline MTIS & 0.59 & 0.18 & 0.06 & 0.16 \\
\hline CCC & 0.08 & 0.04 & 0.04 & 0.28 \\
\hline VEA & 0.07 & 0.07 & 0.56 & 0.31 \\
\hline Score & 0.21 & 0.41 & 0.10 & 0.27 \\
\hline
\end{tabular}

\section{CONCLUDING REMARKS}

In this study, we anlayze the Army Corps Food Supply System via simulation. We make the following observations from the results of simulation experiments:

- Although all battalions are supplied sufficiently in the existing system, the completion time of supply activities is around 6 hours. This is a very long time. Thus, new projects should be initiated to reduce this supply time.

- Enemy attacks and breakdowns delay the duration of food supply. Commanders can minimize this delay in two ways. The first one is to increase the number of maintenance units in the convoys. The second one is to supervise maintenance activities carefully in peace time.

- March technique is the important factor. If the convoys move in-groups, the maximum time-insystem measure increases whereas the $\mathrm{CCC}$ activities become easier. If the $\mathrm{CCC}$ activities are planned perfectly, the convoy commander should prefer to march in split form. Thus, the movement of convoys should be carefully planned.

- The choice of having one or three FSPs should be carefully decided by the planners. The results of AHP technique indicate that three FSPs is preferable. There are already three FSPs in the existing system. One of the FSPs is the main supplier which has the required amount of food in its depots whereas the remaining two FSPs do not have the required amount of food in their depots. It is obvious that remaining FSPs should be operated like the main supply point. Hence, the convoys, supplied from these two FSPs don't need to go to the main supply point and this can reduce the duration of supply activities.

Supply activities are important for Turkish Army. There are many projects undergoing to improve these systems. There are five classes of materials to be supplied at war or peace conditions. Each class of material has different kind of supply chain. A simulation model, which considers all these types, can be developed in future studies.
Also, long-ranged and other sophisticated weapons of the enemy can be included in the model to investigate their potential effects.

\section{REFERENCES}

Balci, O. 1998. Verification, Validation, and Accreditation". In Proceedings of the 1998 Winter Simulation Conference. pp. 42-48.

Banks, J., S. Carson II and B. L. Nelson. 1999. Discrete Event System Simulation. Prentice-Hall, Inc. Upper Saddle River, New Jersey 07458.

Banks, J. 1998. Handbook of Simulation, John Wiley \& Sons, Inc., Newyork.

Kang, K., and Gue, K. R. 1997. Sea Based Logistics: Distribution Problems for Future Global Contingencies". In Proceedings of the 1997 Winter Simulation Conference. pp. 911-916.

Law, A. M., and W. D. Kelton 2000, Simulation Modelling and Analysis, 3rd edition, McGraw-Hill, New York.

Montgomery, D. C. 1991. Design and Analysis of Experiments. John Wiley \& Sons, Inc.

Muslum, S. and Sabuncuoglu, I. 2001. Evaluation of Mobilization and Deployment Plan of an Armored Battalion. Ankara, Turkey.

Parker, S. R. and Williams, P.1997. Integrating Logistics Support Operations". In Proceedings of the 1997 Winter Simulation Conference. pp. 955-960.

Saaty, T. L. 1988. The AnalyticHierachy Process, 2 nd ed. McGraw-Hill New York.

\section{AUTHOR BIOGRAPHIES}

OZAN PEMBE is a military officer in Turkish Army. His research interests include simulation and modelling of military systems. His email address is <ozanpe bilkent. edu.tr>.

IHSAN SABUNCUOGLU, Ph.D., is a Professor of Industrial Engineering at Bilkent University. He teaches and conducts research in the areas of simulation, scheduling and manufacturing systems. He has over 50 technical papers in the literature and serves in the editorial board of various journals. His email address is <saburie bilkent. edu.tr>. 